\title{
Recurrent ameloblastoma of the mandible: Surgical seeding or metastasis of malignant ameloblastoma?
}

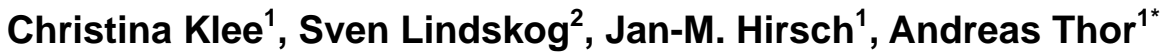 \\ ${ }^{1}$ Department of Surgical Sciences, Oral \& Maxillofacial Surgery, Uppsala University, Uppsala, Sweden; \\ *Corresponding Author: andreas.thor@akademiska.se \\ ${ }^{2}$ Department of Dental Medicine, Karolinska Institute, Stockholm, Sweden
}

Received 24 January 2013; revised 1 April 2013; accepted 15 April 2013

Copyright @ 2013 Christina Klee et al. This is an open access article distributed under the Creative Commons Attribution License, which permits unrestricted use, distribution, and reproduction in any medium, provided the original work is properly cited.

\begin{abstract}
The controversy of surgical seeding or metastasis of a recurrent ameloblastoma is discussed in this paper, where we present a case with a history of 28 years since primary diagnosis including several tumor removals and reconstructive events. 23 years after primary diagnosis, we removed a metastasis from the neck with similar histological features as the primary tumor and the following recurrences of the mandible. We argue that the removed tumor in the neck most possibly has its origin in surgical seeding of cells during earlier resection and reconstruction and not by common ways of metastasis. The seeding of tumor cells during tumor surgery and metastasis rate of malignant ameloblastoma is discussed and the literature in this area is reviewed in the paper.
\end{abstract}

Keywords: Ameloblastoma; Surgical Seeding; Metastasis

\section{INTRODUCTION}

Ameloblastoma is an uncommon disease that represents $1 \%$ of all cysts and tumors diagnosed in the jaws $[1,2]$. These benign slow-growing aggressive neoplasms show a distressing tendency to exhibit locally aggressive behavior and local recurrence in $50 \%$ to $72 \%$ of cases $[3,4]$. Their potential for rare metastasis seems to be poorly understood [5]. Furthermore, tumor seeding during surgery leading to recurrence of the tumor appears to be rarely considered [6]. Hence, in this study we report a case of a 67-year-old female with a recurrent ameloblastoma, which presented in the submandibular region. Histology revealed an ameloblastoma with the same obviously benign growth pattern as in the primary lesion that before had presented in all the preceding surgeries of the jaw.

Although ameloblastoma of the jaws is most often considered by clinicians to be a benign tumor, some of these can be reclassified as malignant when metastases occur [7]. The 2005 World Health Organization (WHO) Classification of Odontogenic Tumors places metastasizing ameloblastoma under the general grouping of odontogenic carcinomas, along with ameloblastic carcinoma [8]. The typical WHO description of a metastasizing (malignant) ameloblastoma is an ameloblastoma that metastasizes in spite of a benign histological appearance [9]. This must be clearly distinguished from the ameloblastic carcinoma (primary type) which is characterized by histological malignant features in both the primary and metastatic sites $[7,10]$.

A review of the literature regarding ameloblastoma indicates that there has been confusion about the terminology which has led to falsification of the frequency of metastasizing (malignant) ameloblastoma compared to ameloblastic carcinoma. Recent literature portends that the incidence of metastasizing (malignant) ameloblastoma has been overestimated while the incidence of ameloblastic carcinoma has been undervalued [11].

\section{CASE REPORT}

In the year 2007 a 67-year-old female was referred to the Department of Oral \& Maxillofacial Surgery, Uppsala University Hospital, for revision of a failed radial forearm flap reconstruction performed 3 years earlier after resection of an ameloblastoma. The patient had underwent numerous operations, in the years 1984, 1989, 1995, 2001, and in 2004 a hemimandibulectomy and reconstruction plate plus radial forearm-flap had been performed.

While planning a reconstruction of the defect with a vascularised fibular osteoseptocutaneous flap graft, a me- 
dical checkup revealed a distinctly enlarged goitre, which considerably displaced the trachea and thus had to be treated primarily. After the thyroidectomy had been performed and the patient had recovered from this intervention, the patient underwent the reconstruction of the mandible in January 2008. During this operation a tumorous nodule in the submandibular/neck area was recognized and excised (Figures 1-4). The histological examination of the sections showed structures of a recurrent ameloblastoma with the typical architecture-islands of epithelium distributed in a fibrous connective tissue stroma.

Retrospectively the micromorphology of the tumor tissue in the biopsies and surgical specimen remained essentially identical over time (Figures 5-8). The tumor presented a follicular pattern with islands and sheaths of

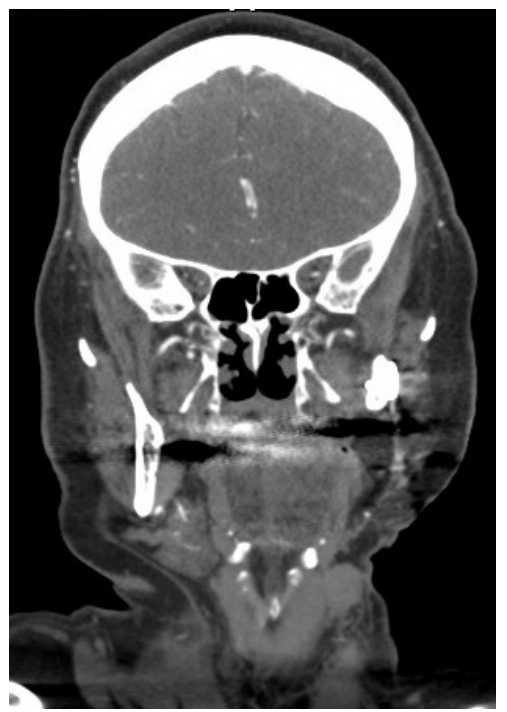

Figure 1. Computed tomography taken preoperatively 2007 showing the tumorous nodule located on the left side of the neck area.

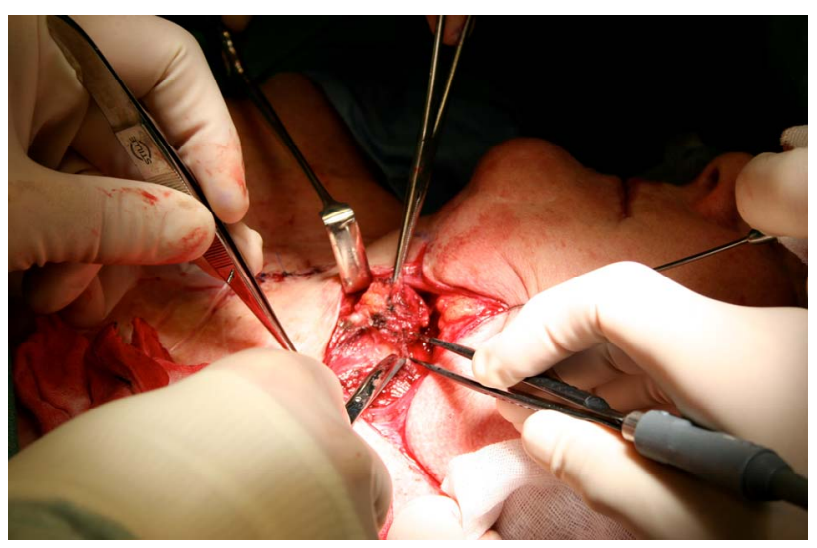

Figure 2. Intra-operative image from the surgical intervention in 2008 , showing the excision of the tumorous nodule in the neck area.

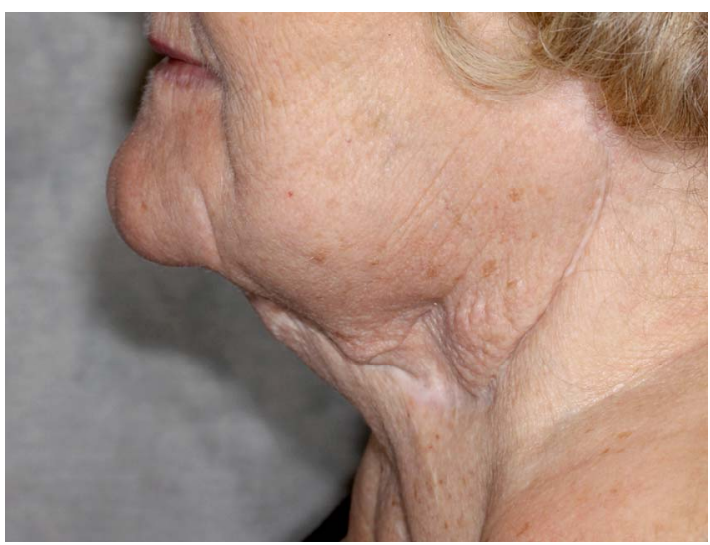

Figure 3. Photograph taken at follow-up 2012 showing the subman-dibular/neck area where the tumorous nodule was excised in 2008.

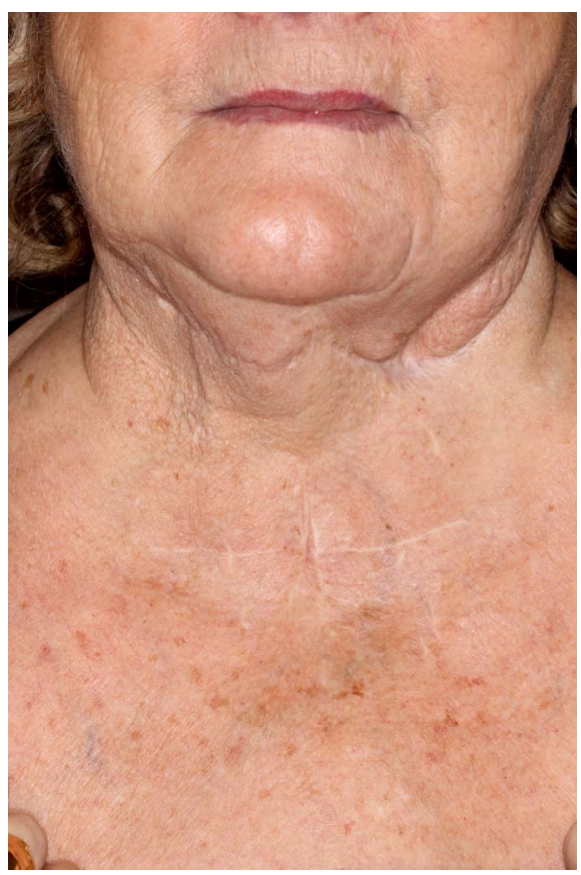

Figure 4. Follow-up 2012. Patient is found to be without any pathological finding 4 years after excision of the tumor in the neck and 28 years after the primary surgery of the mandible.

odontogenic epithelium within a fibrous stroma. Hyalinization of the fibrous stroma frequently surrounded the tumor tissue. At the periphery of the tumor tissue, basal cells varied from columnar to palisaded. The vast majority of the central tumor cells showed squamous differentiation with some cystic spaces and occasional loosely arranged cells resembling stellate reticulum. Mitotic cells were only rarely seen and the cellular pattern was uniform without cellular pleomorphism. Thus, the tumor retained its original differentiation of an acanthomatous follicular ameloblastoma throughout all recurrences.

Subsequent follow-ups have been without pathological 


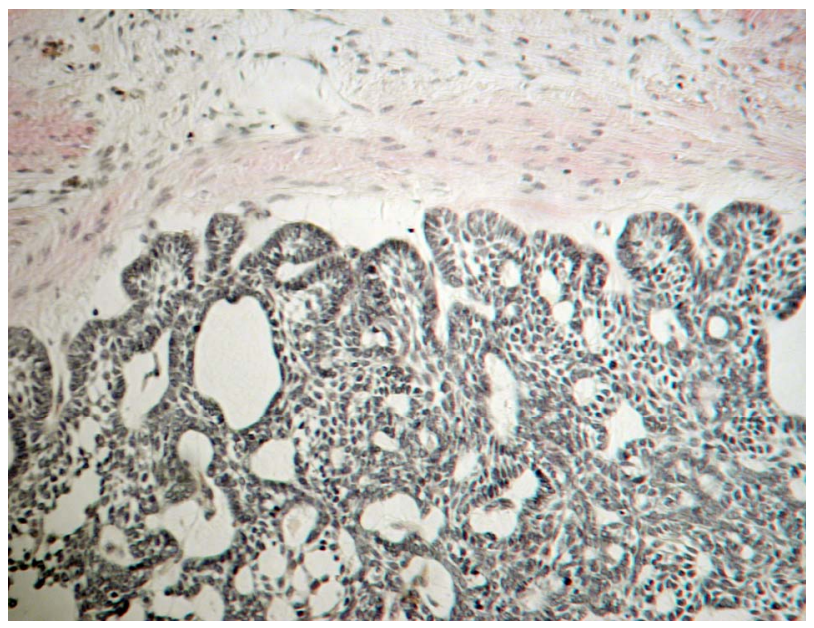

Figure 5. Section from the primary tumor from 1984 showing a follicular pattern within a fibrous stroma. At the periphery, basal cells vary from columnar to cuboidal. The central tumor cells present with squamous differentiation with some cystic spaces and occasional loosely arranged cells resembling stellate reticulum. Van Gieson stain.

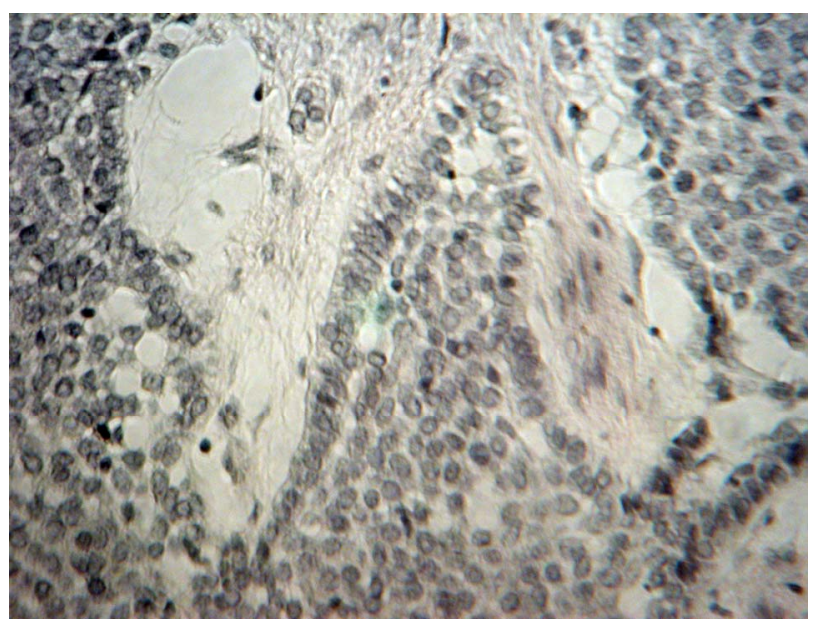

Figure 6. Section from the recurring tumor from 1989 showing sheaths of epithelium with central squamous differentiation outlined by columnar to cuboidal cells. Mitotic cells are only rarely seen and the cellular patter is uniform without cellular pleomorphism. Van Gieson stain.

findings and at present there is no sign of another tumor manifestation at the submandibular/neck site (Figures 3 and 4) of or the site of primary tumor and furthermore no evidence of any spread of the disease.

\section{DISCUSSION}

Metastasizing ameloblastoma is a rare tumor and it is renowned for appearing in approximately $2 \%$ to $5 \%$ of cases [12]. The most recent literature shows that metastasis of well-differentiated ameloblastoma occurs more infrequently than formerly described [11].

This might be due to the fact that some authors do not

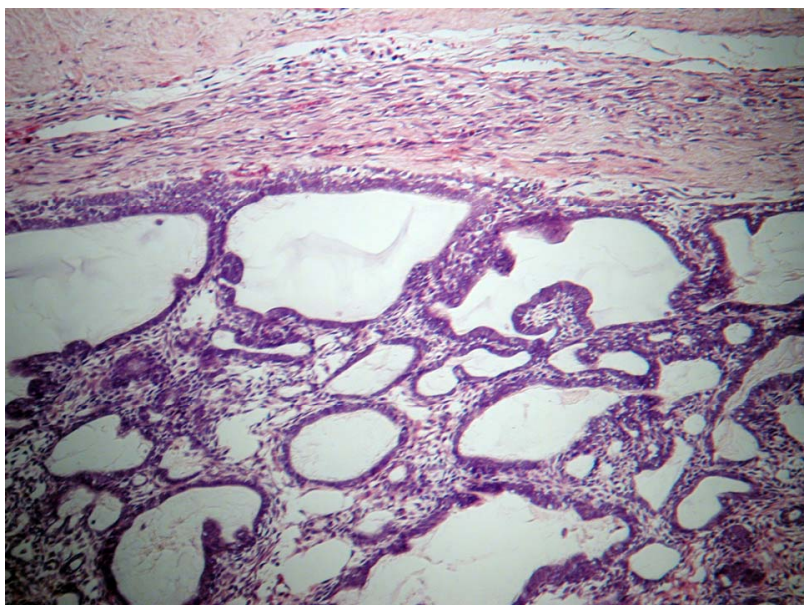

Figure 7. Section from the recurring tumor from 2004. The illustration shows a follicular pattern of the tumor within a fibrous stroma consistent with the micromorphology of the primary tumor from 1984. The central tumor cells present with squamous differentiation with some cystic spaces and occasional loosely arranged cells resembling stellate reticulum. Hematoxylin and eosin stain.

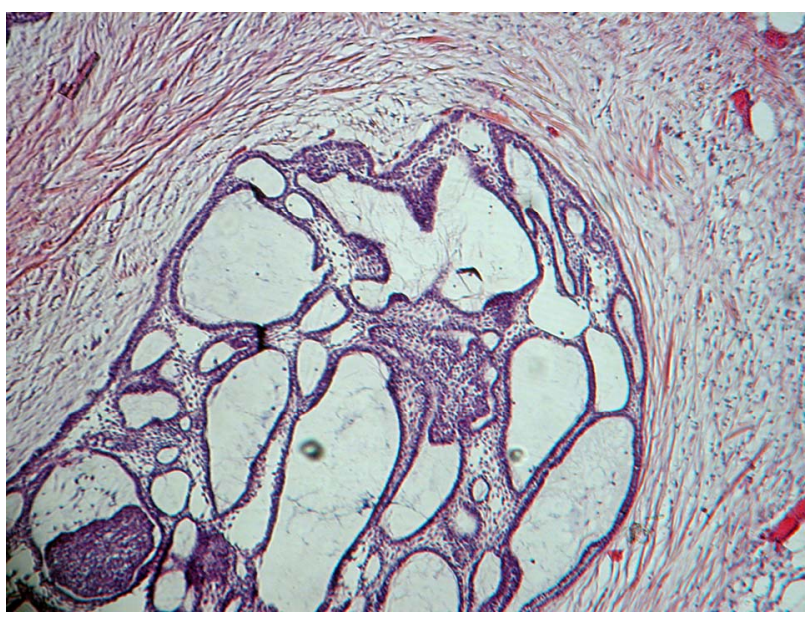

Figure 8. Section from the recurring tumor from 2008 showing a follicular pattern within a fibrous stroma consistent with the micromorphology of the primary tumor from 1984 and the recurring tumor from 2004. Hematoxylin and eosin stain.

distinguish between the two categories of malignancies: metastasizing (malignant) ameloblastoma and ameloblastic carcinoma despite their distinct patterns $[13,14]$. Therefore, the correct number of cases up to now is questionable. According to Ciment and Ciment up to 2002, fewer than 45 cases of ameloblastoma presenting metastasis have been reported [12]. Pursuant to a review by Van Dam et al. including the world literature until 2010 only 27 patient cases could be acknowledged complying with the diagnostic criteria of metastasizing (malignant) ameloblastoma [11].

Many factors have been affiliated with the probability of evolving metastases, including the duration of tumor 
presence, extent of initial disease, multiple surgical procedures, or radiation therapy $[12,15,16]$. However, even in patients without the characteristic history of multiple recurrences and operations, ameloblastoma may appear as a metastatic lesion, usually in the lungs, many years after treatment of the primary tumor [4].

In the majority of cases metastasizing (malignant) ameloblastomas prevail as lung metastases, the rates vary between $71 \%$ - 80\%, followed by cervical lymph node metastases with $15 \%$ - 28\%, vertebrae, and, less frequently, the skull, liver, parotid gland, diaphragm, and brain [7,11,12,16-18].

The mode of spread of malignant ameloblastoma has not been clearly defined. Three routes are commonly mentioned: hematogenous, lymphatic, and by aspiration [15]. Vorzimer and Perla observed tumor casts within the bronchi and bronchioli [19], which led investigators to believe that the metastatic mechanism was by aspiration $[4,15,20]$. Some controversies are apparent when reviewing the literature, because pulmonary metastatic lesions are most commonly found bilaterally, presenting multiple nodules, which supports the theory of hematogenous spread $[15,20]$. Since there have been several reports of extrapulmonary spread, clearly metastases also occur by the hematogenous or lymphatic route, possibly due to disruption of the tumor and vessels during surgical resection [7,21]. In contrast, according to Kunze et al., the pulmonary capillaries evidently provide an effective barrier for ameloblastoma cells and prevent further dissemination into the systemic circulation, since only some patients develop additional extrapulmonary metastases [20].

Although scarcely discussed in the current literature the possibility of tumor cell implantation during surgical procedure must be emphasized. We strongly suspect a intraoperative seeding of tumor cells in our patient which resulted in recurrence of ameloblastoma in the submandibular region.

The most important element in therapy and management of ameloblastoma is adequate treatment of the primary lesion. Multiple surgeries significantly increase the risk of metastases and curettage opens pathways for dissemination of the tumor to adjacent structures which may lead to surgical seeding during operation [15,22]. Therefore, en-bloc resection is the method of choice, using a 10 - to $15-\mathrm{mm}$ safety margin of normal bone, wherever possible, in order to prevent violating the tumor boundaries [22].

Isolated and discrete lung metastases, particularly in the lung periphery have been treated by open thoracotomy and wedge resection, or even by lobotomy, depending on the number of lesions and their location $[3,15,21]$. Significant resection, with preservation of as much viable lung tissue as possible, has been the treat- ment of choice, since this is the only way to offer a significant disease-free interval. Chemotherapy has occasionally been used, with variable results, in limited cases presenting only a reduction in the size of the tumor; however, in most cases, it produced no effective improvement $[3,15]$. Radiotherapy is recommended for inoperable metastatic deposits, but the response is unpredictable and, consequently, radiotherapy should be used only for palliative care [12,15,17].

According to a recently published review by Dam et al. the average time from diagnosis of primary to metastasis is 18 years [11]. Our patient showed a recurrent ameloblastoma about 23 years after the primary tumor diagnosis. The median disease-free interval of previously reported metastatic ameloblastoma cases was 9 years [17]. Our patient underwent numerous operations and the metastasis occurred 3 years after hemimandibulectomy and reconstruction plate plus radial forearm-flap. However, it is important to note that this metastatic lesion was found incidentally, since the patient presented no symptoms in reference to her tumor.

\section{REFERENCES}

[1] Waldron, C. (2002) Odontogenic cysts and tumors. In: Neville, B.W., Damm, D.D., Allen, C.M. and Bouquot, J.E., Eds, Oral and maxillofacial pathology, WB Saunders, Philadelphia, 589-704.

[2] Walke, V.A., Munshi, M.M., Raut, W.K. and Sudhakar, K.B. (2008) Cytological diagnosis of acanthomatous ameloblastoma. Journal of cytology, 25, 62.

[3] Campbell, D., Jeffrey, R.R., Wallis, F., Hulks, G. and Kerr, K.M. (2003) Metastatic pulmonary ameloblastoma. An unusual case. British Journal of Oral and Maxillofacial Surgery, 41, 194-196. doi:10.1016/S0266-4356(03)00046-9

[4] Clay, R.P., Weiland, L.H. and Jackson, I.T. (1989) Ameloblastoma metastatic to the lung. Annals of Plastic Surgery, 22, 160-162. doi:10.1097/00000637-198902000-00013

[5] Black, C.C., Addante, R.R. and Mohila, C.A. (2010) Intraosseous ameloblastoma. Oral Surgery, Oral Medicine, Oral Pathology, Oral Radiology Endodontology, 110, 585-592. doi:10.1016/j.tripleo.2010.02.040

[6] Ferretti, C., Polakow, R. and Coleman, H. (2000) Recurrent ameloblastoma: Report of 2 cases. Journal of Oral and Maxillofacial Surgery, 58, 800-804. doi:10.1053/joms.2000.7271

[7] Verneuil, A., Sapp, P., Huang, C. and Abemayor, E. (2002) Malignant ameloblastoma: Classification, diagnostic, and therapeutic challenges. American Journal of Otolaryngology, 23, 44-48. doi:10.1053/ajot.2002.28769

[8] Barnes, L., Eveson, J.W., Reichart, P. and Sidransky, D. (2005) World Health Organization classification of tumours pathology and genetics of head and neck tumours, Odontogenic tumours. IARC Press, Lyon, 283-328. 
[9] Berger, A.J., Son, J. and Desai, N.K. (2012) Malignant ameloblastoma: Concurrent presentation of primary and distant disease and review of the literature. Journal of Oral and Maxillofacial Surgery, 10, 2316-2326. doi:10.1016/j.joms.2011.11.004

[10] Hayakawa, K., Hayashi, E., Aoyagi, T., Hata, M., Kuramoto, C., Tonogi, M., Yamane, G.Y. and Tanaka, Y. (2004) Metastatic malignant ameloblastoma of the kidneys. International Journal of Urology, 11, 424-426. doi:10.1111/j.1442-2042.2004.00822.x

[11] Van Dam, S.D., Unni, K.K. and Keller, E.E. (2010) Metastasizing (malignant) ameloblastoma: Review of a unique histopathologic entity and report of Mayo Clinic experience. Journal of Oral and Maxillofacial Surgery, 68, 2962-2974. doi:10.1016/j.joms.2010.05.084

[12] Ciment, L.M. and Ciment, A.J. (2002) Malignant ameloblastoma metastatic to the lungs 29 years after primary resection: A case report. Chest, 121, 1359-1361. doi:10.1378/chest.121.4.1359

[13] Mosqueda Taylor, A., Meneses Garcia, A., Ruiz Godoy Rivera, L.M., Suarez Roa Mde, L. and Luna Ortiz, K. (2003) Malignant odontogenic tumors. A retrospective and collaborative study of seven cases. Medicina Oral, 8, 110-121.

[14] Kuramoto, C., Morisaki, S., Tonogi, M., Yamane, G. and Tanaka, Y. (2003) A case of malignant ameloblastoma that metastasized throughout the body. Oral Surgery, Oral Medicine, Oral Pathology, Oral Radiology Endodontology, 95, 429.

[15] Henderson, J.M., Sonnet, J.R., Schlesinger, C. and Ord, R.A. (1999) Pulmonary metastasis of ameloblastoma: Case report and review of the literature. Oral Surgery, Oral Medicine, Oral Pathology, Oral Radiology Endo- dontology, 88, 170-176. doi:10.1016/S1079-2104(99)70113-7

[16] Zwahlen, R.A., Vogt, P., Fischer, F.S. and Gratz, K.W. (2003) Case report: Myocardial metastasis of a maxillary malignant ameloblastoma. Journal of Oral and Maxillofacial Surgery, 61, 731-734. doi:10.1053/joms.2003.50146

[17] Laughlin, E.H. (1989) Metastasizing ameloblastoma. Cancer, 64, 776-780. doi:10.1002/1097-0142(19890801)64:3<776::AID-CNCR 2820640335>3.0.CO;2-8

[18] Dissanayake, R.K., Jayasooriya, P.R., Siriwardena, D.J. and Tilakaratne, W.M. (2011) Review of metastasizing (malignant) ameloblastoma (METAM): Pattern of metastasis and treatment. Oral Surgery, Oral Medicine, Oral Pathology, Oral Radiology Endodontology, 111, 734-741. doi:10.1016/j.tripleo.2010.12.018

[19] Vorzimer, J. and Perla, D. (1932) An instance of adamantinoma of the jaw with metastases to the right lung. American Journal of Pathology, 8, 445-454.

[20] Kunze, E., Donath, K., Luhr, H.G., Engelhardt, W. and De Vivie, R. (1985) Biology of metastasizing ameloblastoma. Pathol Research and Practice, 180, 526-535. doi:10.1016/S0344-0338(85)80017-0

[21] Newman, L., Howells, G.L., Coghlan, K.M., DiBiase, A. and Williams, D.M. (1995) Malignant ameloblastoma revisited. British Journal of Oral and Maxillofacial Surgery, 33, 47-50. doi:10.1016/0266-4356(95)90087-X

[22] Zwahlen, R.A. and Gratz, K.W. (2002) Maxillary ameloblastomas: A review of the literature and of a 15-year database. Journal of Craniomaxillofacial Surgery, 30, 273279. 